\title{
A Study on Minimization of Injury and Accidental Causes in Different Operational Sections of RMG Industries in Bangladesh
}

\author{
Israt Parveen, Md. Iqbal Mahmud*, Anik Kumar Mondol, Mosammot Nelufa Akter, Shima Shil \\ Department of Textile Engineering, Mawlana Bhashani Science and Technology University, Santosh, Tangail, Bangladesh \\ Email address: \\ mimchanchal@gmail.com (Md. I. Mahmud) \\ ${ }^{*}$ Corresponding author
}

\section{To cite this article:}

Israt Parveen, Md. Iqbal Mahmud, Anik Kumar Mondol, Mosammot Nelufa Akter, Shima Shil. A Study on Minimization of Injury and Accidental Causes in Different Operational Sections of RMG Industries in Bangladesh. International Journal of Industrial and Manufacturing Systems Engineering. Vol. 4, No. 1, 2019, pp. 10-18. doi: 10.11648/j.ijimse.20190401.13

Received: March 4, 2019; Accepted: April 9, 2019; Published: April 29, 2019

\begin{abstract}
The primary objective of this study is to investigate the industrial accident in readymade garments (RMG) industries and find out the ways how this risk of injuries and accidents can be mitigating by implementing safety rules and suggestions. The paper discusses in brief the risk of injury and accidental causes of workers in various sections like dyeing, cutting, sewing, printing and finishing of RMG industries based upon the industrial environment and working conditions. The sample respondents are selected from the different industries in Tangail district. Purposive sampling technique is followed for data collection, where different level of respondents is interviewed for collecting information from selective garments industry. After analyzing the collected data, the major accidental causes and injuries faced by the workers in those selective units are indicated for which there have been noticed a massive fall down of workers' efficiency. Indicating those problems, improvement proposals are given to those industries and implemented over a course of month. From the proposed improvement proposal, it is found that, the rate of injury and accidental risks have been decreased far better than before and almost all risks can be properly controlled if the managing as well as responsible parties try to follow the risk controlling technique properly.
\end{abstract}

Keywords: Readymade Garment (RMG), Industrial Accidents, Injury, Risk Factor, Remedial Action etc.

\section{Introduction}

Accidents and injury in an industry endanger the safety of workers, adversely affect livelihood of the workers and their families, and those living in the vicinity of the industry. Thousands of people are killed and injured in industrial accidents every year. According to the ILO, occupational accidents and work-related diseases cause over 2.3 million fatalities annually, of which over 350,000 are caused by occupational accidents. These result in immeasurable human sufferings and major economic losses for entrepreneurs and economies as a whole; around 4\% of the world's GDP, or about US\$2.8 trillion, is lost annually in direct and indirect costs $[1,2]$. Different industrial hazards resulted in several initiatives worldwide to protect human life and reduce material damage from industrial accidents, both nationally and internationally [3]. Without workplace safety compliance, it is almost impossible to ensure business sustainability and to survive in global competitive market [4]. Recent accidents around the world have highlighted the potential hazards inherent in many industrial operations.

In Bangladesh, all the garment factories are located in the residential and commercial area of Dhaka, Chittagong, Narayangonj, Tongi, Gazipur, Saver, Tangail etc. Besides, most of the garment factories hardly comply with safety rules. So, naturally the garments workers have to suffer a lot of occupational accidents. The occupational health and safety condition of the workers belonged to the industry, is getting more critical and complicated gradually [5]. That's why, necessary measures need to be undertaken to prevent the occurrence of such accidents through the introduction of safer process technologies, the improved performance of 
safety devices, and by the reduction of human error. The most effective accident and disease prevention begins when work processes are still in the design stage, when safe conditions can be built into the work process. In order to develop a successful health and safety program, it is essential that there should be strong management commitment and worker participation in the effort to maintain a safe and healthy workplace [6]. This study performs and identifies the safety measures in dyeing, cutting, sewing, printing and finishing units of a garment industry that plays an important role in accident and injury prevention or reduction in the workplace.

\section{Material and Method}

\subsection{Material}

In this study, various types of materials i.e. tools and machineries are used from different sections of the garment industry, such as in dyeing section (stenter machine, dyeing machine, compacting machine, sleeting machine, various toxic chemicals, electric cables, dosing tank), cutting section (straight knife cutting machine, band knife cutting machine, round knife cutting machine), sewing section (plain machine, flat lock machine, Kansai machine, bar tack machine, button holing machine, feed off the arm), printing section (screen, chemical testing machineries, different types of chemicals) and finishing section (different types of chemicals like acid, alkali, adhesives, cleaning solvents).

\subsection{Method}

The legal requirement for risk evaluation or assessment applies to all the operating employees in different sections. The process for carrying out the risk assessment done through a series of steps:

\subsubsection{Conducting Primary Survey}

This research is based on output from primary data from the respondents through a sample survey with the help of interview schedule. The data collection included questionnaire survey and focus group discussion.

\subsubsection{Data Collection}

Consecutively two months' data are collected at the beginning of 2018. The questionnaires are asked systematically and recorded directly on the schedule. The collected data is monitored and reviewed at regular intervals.

\subsubsection{Identifying Hazards Cause Risk}

Risk assessment is the first step to successful risk management. Looking for the hazards and risks those have the potential to cause harm, and identifying operating workers who may be exposed to the hazards. Using workers' knowledge helps to ensure hazards are spotted and workable solutions implemented.

\subsubsection{Evaluating and Prioritizing Risks}

Evaluation of how likely the hazards are lead to harm or injury, and how severe that injury is likely to be. Considering what control measures are in place and whether they are sufficient. The focus for sustainable risk management is on collective protection and preventative measures.

\subsubsection{Deciding on Preventive Action}

Identifying the appropriate measures to eliminate or control the risks. Making list of the preventive measures needed in order of priority, then taking action, involving the operating workers and their representatives in the process. Targeting the underlying problems is the most cost effective method of risk management.

\section{Risk Sources in Different Operating Sections}

\subsection{Risk Sources in Cutting Section}

Lot of injuries face by the working operators in cutting section of the textile industries. Cutting section is a dusty work place as during cutting huge dust is produced. Generally, following causes of injuries are found in cutting unit that faced by the operator. Also figure 1 shows the risk sources in cutting section.

\subsubsection{Fabric Relaxation Rack}

Cutting units are the first section of readymade garments. The fabrics are received from fabric store and kept for relaxation in big rack according to buyer requirements. The rack is usually made of very hard metal structure. During movement/transfer of the racks, operators are injured in leg.

\subsubsection{Scissor Blade}

Scissors have sharp blades which is so risky for hand while cutting the fabric. Unconsciously, many workers suffer in hand or other body organism because of working with the scissors. Continuously using, the handle of scissor creates dark spot on skin. During observation it is noticed that maximum worker is suffering from this hand injury caused by the scissor operation $[7,8]$.

\subsubsection{Rubbing on Floor}

Because of long working hours and work by standing without wearing shoes results leg injury to the workers as the foots are rubbed over the floor continuously. Most of cases operating workers are not allowed to wear shoes on the floor as a result the injury occurred.

\subsubsection{Straight Knife}

Straight knives used in cutting sections are extremely sharp and have high rpm of about 3600 . As it is electricity operated, it causes shock. Moreover, these cutting knives cause both the hand and leg injury to the workers during work.

\subsubsection{Fabric Dust}

During fabric cutting, huge amount of fabric dust is produced which causes asthma, respiratory problem, several skin diseases, eye irritation, visibility problem etc. 


\subsubsection{Band Knife Machine}

Band knife machine is high risky for operators as it has open sharp knife for cutting. Serious accidents may occur if the operators don't wear steel hand gloves during operation.

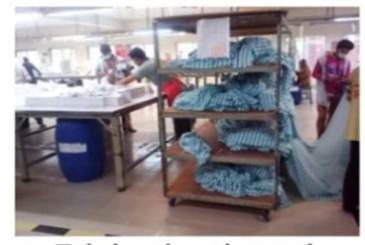

Fabric relaxation rack

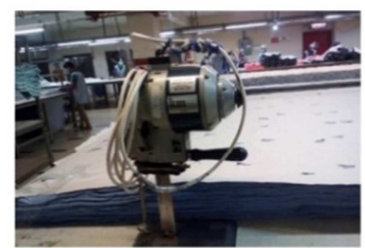

Straight knife

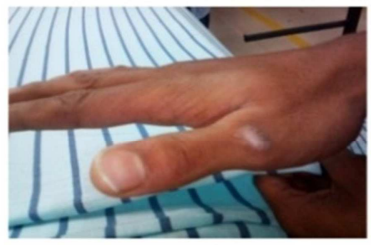

Hand injury by scissor

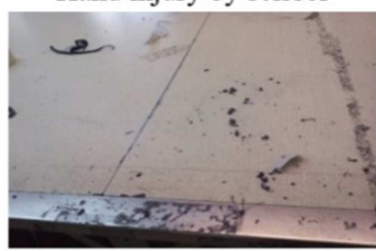

Fabric dust

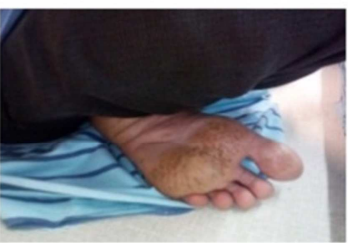

Leg injury by floor rubbing

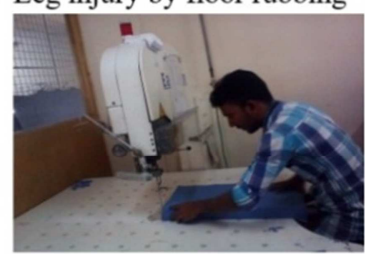

Band knife machine operation

Figure 1. Different risk sources in cutting section.

\subsection{Risk Sources in Sewing and Finishing Section}

Figure 2 shows the risk sources in sewing and finishing section.

\subsubsection{Plain Sewing Machine}

The needles used in plain sewing machine may injure operator's finger during operation. Sometimes needles could break and hit in the eye.

\subsubsection{Flat-Lock and Over-Lock Machine}

Lot of dust produces during the flat-lock and over-lock machine operation. Without using a mask during machine operation could causes various diseases like asthma, lung cancer, bronchitis etc.

\subsubsection{Button Holing, Button Stitch, Snap Button, Button Attach Machine}

Using these types of machine, working needle or button could hurt in the finger, eye or body of the workers. Moreover, because of poor electrical wiring, fire accidents may have occurred.

\subsubsection{Hearing Problems}

In sewing section large number of machines runs together at a time which sometimes causes inflatable noise pollution. With such environment workers feel difficulty to sustain and face problems of headache and hearing; results brain disorder, nerve problem etc.

\subsubsection{Mentally Disorder Problems}

Target oriented production per day led the workers mentally disordered as they always feel pressure from their superior to complete the target production in time. They also face misbehavior and insulting situation from their top management. Sometime they are being abused by the management.

\subsubsection{Musculoskeletal Disorders}

Musculoskeletal disorders (MSDs) are the most common work-related health problem, with almost one in four workers reporting backache and one in five complaining of muscular pains. Manual handling, the lifting, holding, putting down, pushing, pulling, carrying or movement of a load, is the largest cause of injury in the textiles sector. Manual handling can cause either cumulative disorder from the gradual deterioration of the musculoskeletal system, such as lower back pain, or acute trauma such as cuts or fractures due to accidents. In the textile industry, risk factors for MSDs include: (a) working in awkward postures such as during sewing, cutting, product control and packaging; (b) repetitive movements such as during turning, cutting, product control and packaging and (c) fatigue from manual handling, during the storage, inspection, treatment, shipping, finishing and checking of garments [9].

\subsubsection{Exposure to Dusts and Fibers}

The exposure of workers to dusts from material such as silk, cotton, wool, flax, hemp, sisal and polyester can occur during weaving, cutting, sewing, and packaging. Division of tasks along gender lines may mean that women are exposed to organic dusts more than men with respiratory nasal or bladder cancer.

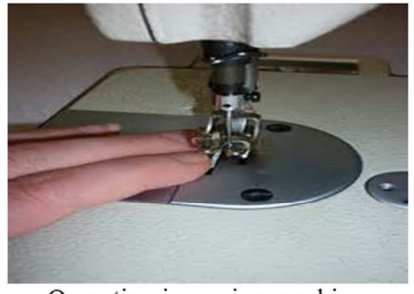

Operation in sewing machine

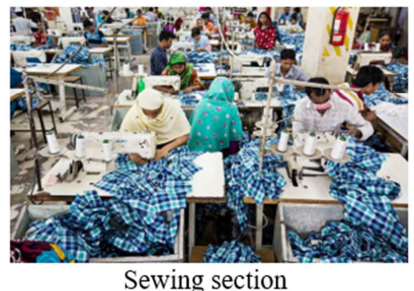

Sewing section

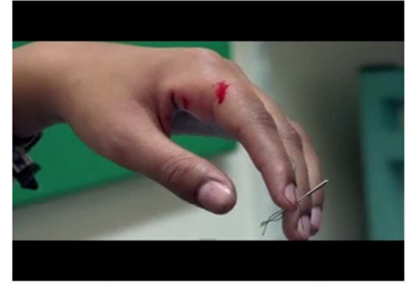

Finger injury by needle

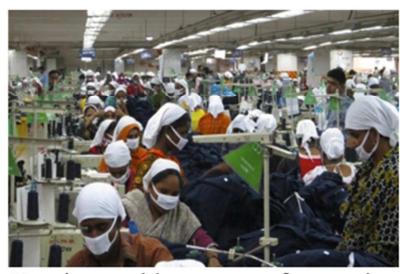

Hearing problems occur from noise

Figure 2. Different risk sources in sewing and finishing section. 


\subsection{Risk Sources in Dyeing Section}

There are numerous health and safety features associated with the dyeing section. First of all, it is important to take necessary steps to protect worker's health and safety by recognizing the workplace hazards. Most hazards encountered fall into three main categories such as physical hazard, chemical hazard and biological hazard [10]. In dyeing section, chemical exposure from the processing and dyeing of materials, exposure to cotton and other organic dusts which can affect the throat and lungs, musculoskeletal stresses, noise exposure which can lead to hearing loss, temperature and ventilation which can lead to fatigue and dehydration if temperatures are too high and working hours and breaks including access to food, drinks and bathroom facilities [11]. Figure 3 shows various risk sources in dyeing section.

\subsubsection{Hazards in Physical Lab}

In physical lab, research facilities have significant physical hazards. These include electrical safety hazards, ergonomic hazards, handling sharps and basic housekeeping issues. Here found various types of chemicals such as different types of acids, alkalis, fixing agents, sequestering agents etc. These chemicals are hazardous for working operator's health.

\subsubsection{Hazards in Testing Lab}

In testing lab, various types of heavy machineries are used. Here operators are injured because heavy equipment's fall onto their legs or hands. Besides, during working with dryer there have chances to be burn their hands which can lead to serious skin injury.

\subsubsection{Risk in Dyeing Processing Area}

In dyeing section, lot of risk may occur from various process machineries. In scouring process, sometimes caustic soda and hydrogen peroxide mixed together which accidentally create fire that may lead injury on faces. During mixing chemicals in the dosing tank, it may fall over the operator hands, face, body etc. Again, when they input the grey fabric into the machine, risk in involved. In stenter machine, high temperature is used for drying the fabric. This temperature often creates the fire which may occur serious accident on the floor.
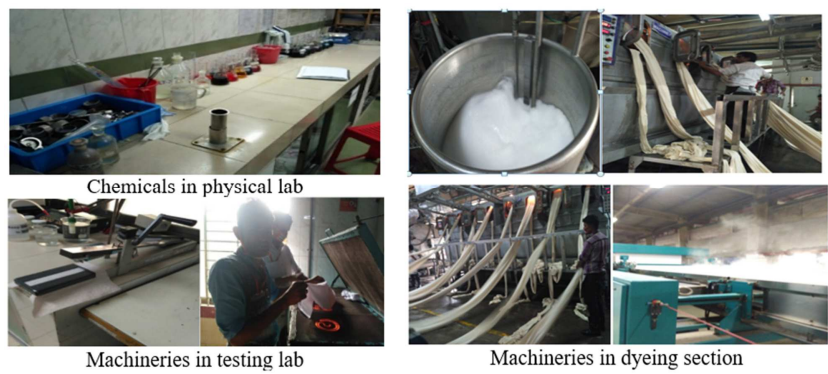

Figure 3. Different risk sources in dyeing section.

\subsection{Risk Sources in Printing Section}

In printing section, injury of the operator mainly causes due to unconscious use of the printing screen and by the chemicals used in printing process. Most printing machinery's accidents occur at presses while making ready, attending to web breaks/webbing-up, freeing blockages, machine setting, press cleaning, addition of substrates/inks and maintenance. The most common injuries in printing section are lacerations, cuts and bruises, fractures/dislocation and crushing injuries to the fingers or hand. Fatal accidents have occurred on platens and other printing machines. Figure 4 shows different risk sources in printing section. In addition, some common causes of printing machinery accidents are being drawn into in-running nips of rollers, contact with dangerous moving parts and entanglement with rotating parts.

\subsubsection{Unconscious Use of the Printing Screen}

Screen printing is a printing technique whereby a mesh is used to transfer ink onto a substrate, except in areas made impermeable to the ink by a blocking stencil. Traditionally the process was called screen printing or silkscreen printing because silk was used in the process prior to the invention of polyester mesh. Sometimes, unconscious use of the printing screen process may affect workers hand and skin.

\subsubsection{Chemical in Printing Section}

Textile industry consumes a large number of chemicals in the processing and manufacturing of textiles. There are many accidents arising each year from the exposure to chemicals used in textile mills. Different types of chemicals are used in printing section such as acid, alkali, adhesives, cleaning solvents etc.

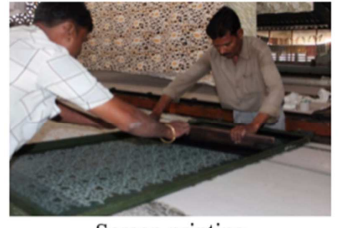

Screen printing

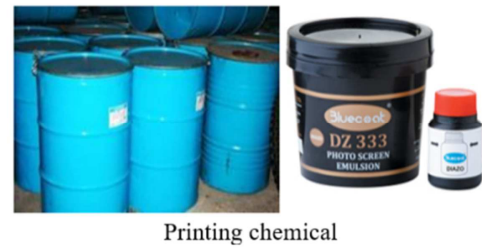

Printing chemical
Figure 4. Different risk sources in printing section.

\section{Collection of Data}

Table-1 shows types, causes and number of injury occurred in cutting, sewing and finishing, dyeing and printing section of a garment industry during January 2018. The data is taken on the basis of risk sources described in section 3 .

Table 1. Injury and accident occurred in different operating section in January 2018.

\begin{tabular}{|c|c|c|c|c|}
\hline $\begin{array}{l}\text { Operating } \\
\text { Section }\end{array}$ & $\begin{array}{l}\text { Sl. } \\
\text { No. }\end{array}$ & Types of Injury & $\begin{array}{l}\text { Causes of } \\
\text { Injury }\end{array}$ & $\begin{array}{l}\text { Number of } \\
\text { Injury Occurred }\end{array}$ \\
\hline \multirow{7}{*}{$\begin{array}{l}\text { Cutting } \\
\text { section }\end{array}$} & 1 & Hand injury & Band knife & 5 \\
\hline & 2 & Hand injury & Straight knife & 2 \\
\hline & 3 & Leg injury & Straight knife & 3 \\
\hline & 4 & Hand injury & Scissor & 7 \\
\hline & 5 & Leg injury & Rack & 4 \\
\hline & 6 & $\begin{array}{l}\text { Respiratory } \\
\text { problem }\end{array}$ & Dust & 10 \\
\hline & 7 & Foot injury & Floor rubbing & 15 \\
\hline \multirow{2}{*}{$\begin{array}{l}\text { Sewing } \\
\text { and }\end{array}$} & 1 & Asthma & Dust & 13 \\
\hline & 2 & Bronchitis & Dust & 1 \\
\hline
\end{tabular}




\begin{tabular}{|c|c|c|c|c|}
\hline $\begin{array}{l}\text { Operating } \\
\text { Section }\end{array}$ & $\begin{array}{l}\text { Sl. } \\
\text { No. }\end{array}$ & Types of Injury & $\begin{array}{l}\text { Causes of } \\
\text { Injury } \\
\end{array}$ & $\begin{array}{l}\text { Number of } \\
\text { Injury Occurred }\end{array}$ \\
\hline \multirow{12}{*}{$\begin{array}{l}\text { finishing } \\
\text { section }\end{array}$} & 3 & Finger injury & Needle & 16 \\
\hline & 4 & Eye injury & Needle & 1 \\
\hline & 5 & $\begin{array}{l}\text { Respiratory } \\
\text { problem }\end{array}$ & Dust & 17 \\
\hline & 6 & Hand burn & Ironing & 8 \\
\hline & 7 & Eye irritation & $\begin{array}{l}\text { Chemicals in } \\
\text { spot removal }\end{array}$ & 2 \\
\hline & 8 & Hand burn & $\begin{array}{l}\text { Chemicals in } \\
\text { spot removal }\end{array}$ & 1 \\
\hline & 9 & Hearing problem & Noise & 13 \\
\hline & 10 & Mental problem & Abuse & 10 \\
\hline & 1 & Eye irritation & Chemicals & 9 \\
\hline & 2 & Hand burning & Dosing tank & 5 \\
\hline & 3 & Fire & Stenter machine & 1 \\
\hline & 4 & Hand burning & Chemicals & 7 \\
\hline \multirow[t]{6}{*}{$\begin{array}{l}\text { Dyeing } \\
\text { section }\end{array}$} & 5 & Muscle disorder & $\begin{array}{l}\text { Loading and } \\
\text { unloading }\end{array}$ & 3 \\
\hline & 6 & Body burn & Stenter machine & 1 \\
\hline & 7 & Hand burning & Heater & 2 \\
\hline & 8 & Electric shock & Lose cable & 1 \\
\hline & 9 & Leg burn & Chemicals & 1 \\
\hline & 1 & Hand injury & Screen frame & 5 \\
\hline \multirow{3}{*}{$\begin{array}{l}\text { Printing } \\
\text { section }\end{array}$} & 2 & Eye irritation & Chemicals & 4 \\
\hline & 3 & Asthma & Odor & 7 \\
\hline & 4 & Hand injury & Chemicals & 4 \\
\hline
\end{tabular}

\section{Data Analysis and Action Plans to Minimize the Injury and Accidents}

\subsection{Action Plans for Cutting Section}

Following action plans are made for the cutting section to minimize the injury and accidents:

(a) There should be adequate warning signals to indicate when atomized cutting table or the blade is in motion.

(b) For regular changing and disposing of cutter blades, documentation of data must be maintained [12].

(c) To prevent all dirt, fluff, fly and off cuts an effective cleaning system in operation should be strictly followed.

(d) Automatic adjustable guards should be fitted with the machine to fully cover the unprotected part of the cutting blade.

(e) Electric conductor position should be regularly checked.

(f) Marking the danger areas and access should be restricted by barriers, particularly at cutting tables.

(g) During cutting or handling blades, five-finger chain mail gloves should be provided to workers that must be worn.

(h) When layup machine is in motion, trip guards should be used.

(i) Checking the condition whether the light, guard and table fittings are in accurate position.

(j) Old blades should be disposed of in a safe manner that precludes their use as DIY hand [13].

\subsection{Action Plans for Sewing and Finishing Section}

Following action plans are made for the sewing and finishing section to minimize the injury and accidents:

(a) Machine safety cover, needle guard and eye guard should be used.

(b) Electric connection and electric fault should be checked before starting regular working.

(c) Safety tools like rubber mat \& musk must be used during working.

(d) Tools and parts must be controlled and investigate through proper maintenance system.

(e) For flexibility in working, minimum distance should be kept among operator.

(f) A planned preventive maintenance program system is crucial for safety, legality and quality, which is fully implemented.

(g) Mental harassment and abusing worker should be strictly avoided to ensure safe working environment.

(h) Safety environment should be ensured to avoid contamination risk to the surrounding area [14].

(i) Repairing must be completed by approved contractors or the equipment manufacturer on due time to keep safe from any accident.

(j) Risk assessments must be completed by service provider to ensure a product is completely safe from risk.

\subsection{Action Plans for Dyeing Section}

Following action plans are made for the dyeing section to minimize the injury and accidents:

(a) Smoking or open fires should be outlawed where inflammable substances are present.

(b) Heavy objects should be marked to avoid musculoskeletal mishaps and unavoidable physical injury.

(c) Hand wash, showers and eye washes should be made available in every washroom

(d) Fire alarms, emergency exit and emergency lights should be existent to avoid fire accident [15].

(e) In research laboratory, store room and factory floor and other areas where there is always risk of contamination by chemicals, is not safe to eat food due to contamination risk.

(f) Sufficient fire extinguishers should be made available and emergency exit path should be clearly indicated with red mark.

(g) Fire hazardous substances should be clearly labeled with the universally accepted symbol.

(h) Hazardous chemicals should be marked in proper technique to easily recognize and understand for safely usage [16].

\subsection{Action Plans for Printing Section}

Following action plans are made for the printing section to minimize the injury and accidents:

\subsubsection{Chemical Safety}

To manage chemical risks, the first thing is to identify the hazards that could give rise to risks, followed by eliminating the risks as practicable. There are three basic steps for 
managing risks of chemicals and this are-

Identify the chemicals that are used in the workplace and the hazards associated with them.

Assessing the risks from chemicals used in processes and workplace.

Control measures to mitigate risk that includes various recognized control measures to eliminate or reduce the risks [17].

The control measures are required to be implemented in a factory to ensure chemical safety. The recommended hierarchy of control measures is:

(a) Eliminate the hazardous chemical

(b) Substitute with a less hazardous chemical

(c) Install engineering controls

(d) Use personal protective equipment (PPE).

\subsubsection{Labels}

The most important sources of information on the hazards of the chemicals are the label. It should be ensured that any chemical is supplied with a label attached on container. The label gives information on the chemical or product name, the chemical hazards and the precautions should take into account to ensure safe handling and use.

\subsubsection{Safety Data Sheet (SDS)}

Another important source of information on the hazards of the chemicals is the safety data sheet (SDS). It is must to have a SDS for each hazardous chemical that is used in the process and workplace. These SDS should be kept at identifiable place where it can be accessed from employees and emergency services in case of chemical accident. SDS should:

(a) Be provided for all chemicals used at the workplace especially those which are classified as hazardous.

(b) Be prepared by a competent person (MSDS/SDS-Author).

(c) Be clear and understandable.

(d) Be provided free of charge.

(e) Be provided no later than at the time of first delivery of chemical product

(f) Be provided upon update or revision to every use [18].

\section{Result and Discussion}

Considering the risk sources at different operating sections and by imposing the necessary action plans in each section, number of injury and accidents are observed in February 2018. It is found that, number of injury and accidents minimizes at significant level. Graphical presentations below show the minimization of injury and accidents in different sections.

\subsection{Minimization of Injury and Accidents in Cutting Section}

Risk assessment is carried out in cutting section. Before implementation the action plans, the injury level of the workers is collected by monitoring and assessing the risk in the month of January 2018 (table-1) and after implementation of action plans in cutting section, the injury level of the workers is collected in the month of February 2018. Figure 5 shows reduces of injury and accidents occurred in February 2018 compare to January 2018 in cutting section.

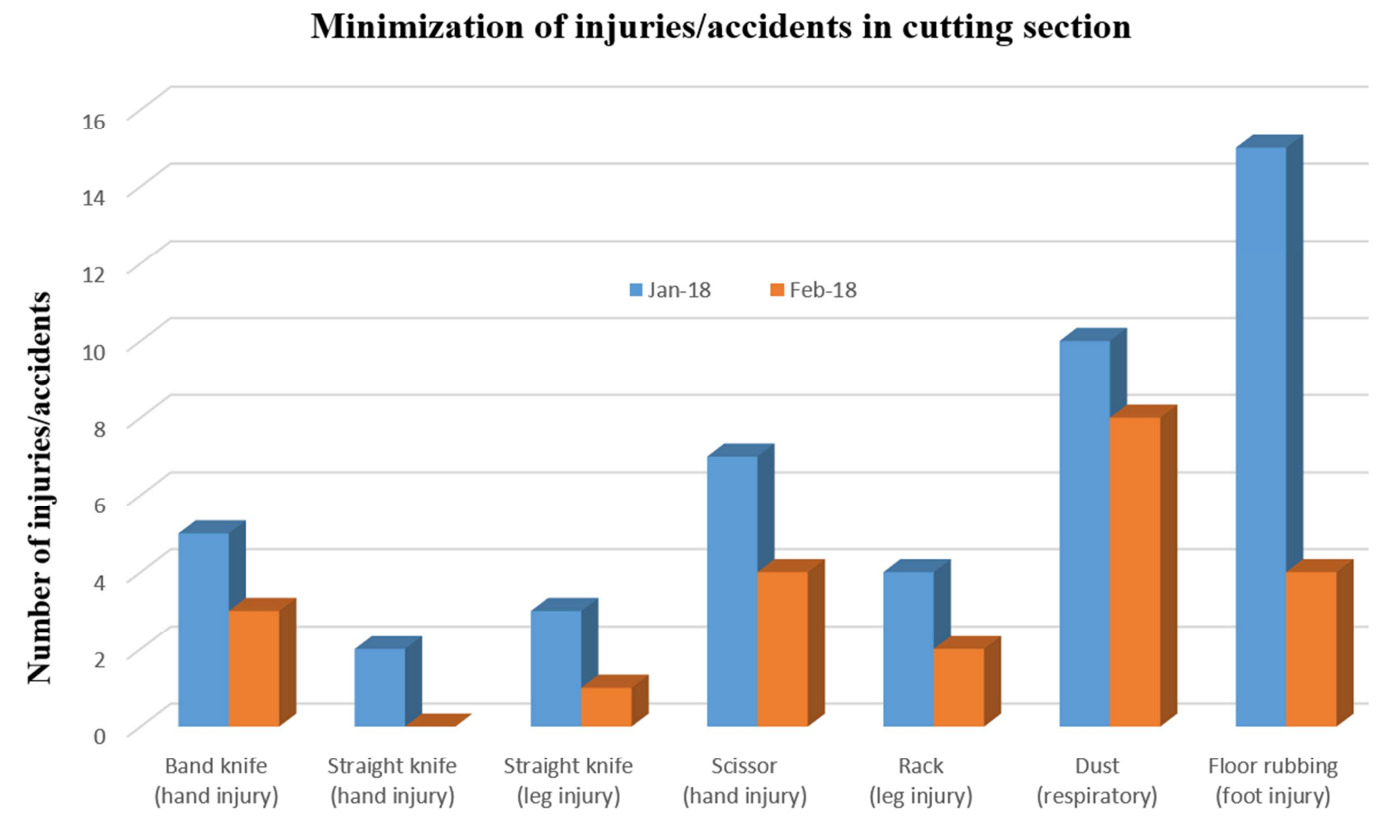

Causes of injury

Figure 5. Comparison of injury/accident reduction in cutting section between the months.

\subsection{Minimization of Injury and Accidents in Sewing and Finishing Section}

Risk assessment is carried out in sewing and finishing section. Before implementation the action plans, the injury level of the workers is collected by monitoring and assessing the risk in the month of January 2018 (table-1) and after implementation of action plans in sewing and finishing 
section, the injury level of the workers is collected in the month of February 2018. Figure 6 shows reduces of injury and accidents occurred in February 2018 compare to January 2018 in sewing and finishing.

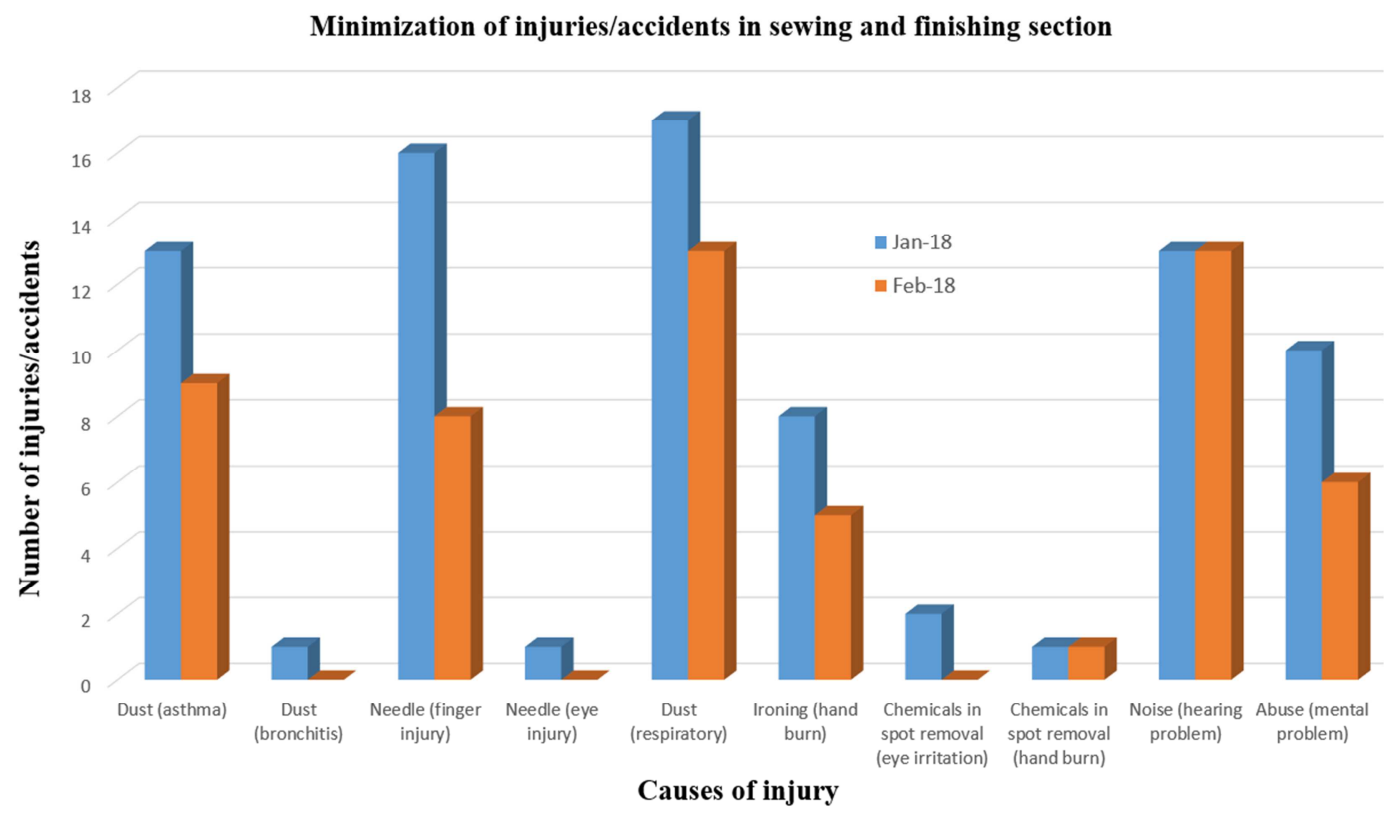

Figure 6. Comparison of injury/accident reduction in sewing and finishing section between the months.

\subsection{Minimization of Injury and Accidents in Dyeing Section}

Risk assessment is carried out in dyeing section. Before implementation the action plans, the injury level of the workers is collected by monitoring and assessing the risk in the month of January 2018 (table-1) and after implementation of action plans in dyeing section, the injury level of the workers is collected in the month of February 2018. Figure 7 shows reduces of injury and accidents occurred in February 2018 compare to January 2018 in dyeing section.

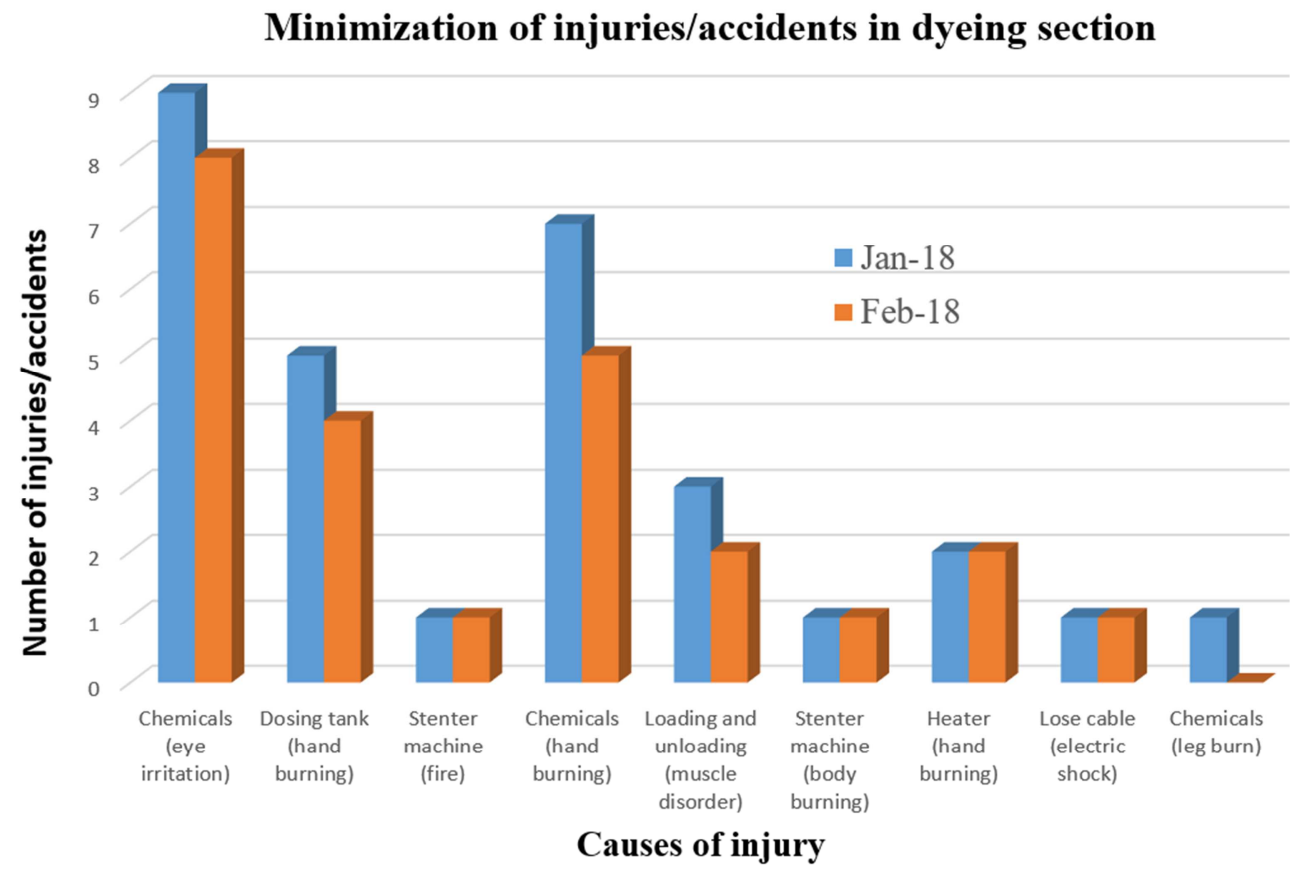

Figure 7. Comparison of injury/accident reduction in dyeing section between the months.

\subsection{Minimization of Injury and Accidents in Printing Section}

Risk assessment is carried out in printing section. Before implementation the action plans, the injury level of the workers is collected by monitoring and assessing the risk in the month of January 2018 (table-1) and after implementation of action plans in printing section, the injury level of the 
workers is collected in the month of February 2018. Figure 8 2018 compare to January 2018 in printing section. shows reduces of injury and accidents occurred in February

\section{Minimization of injuries/accidents in printing section}

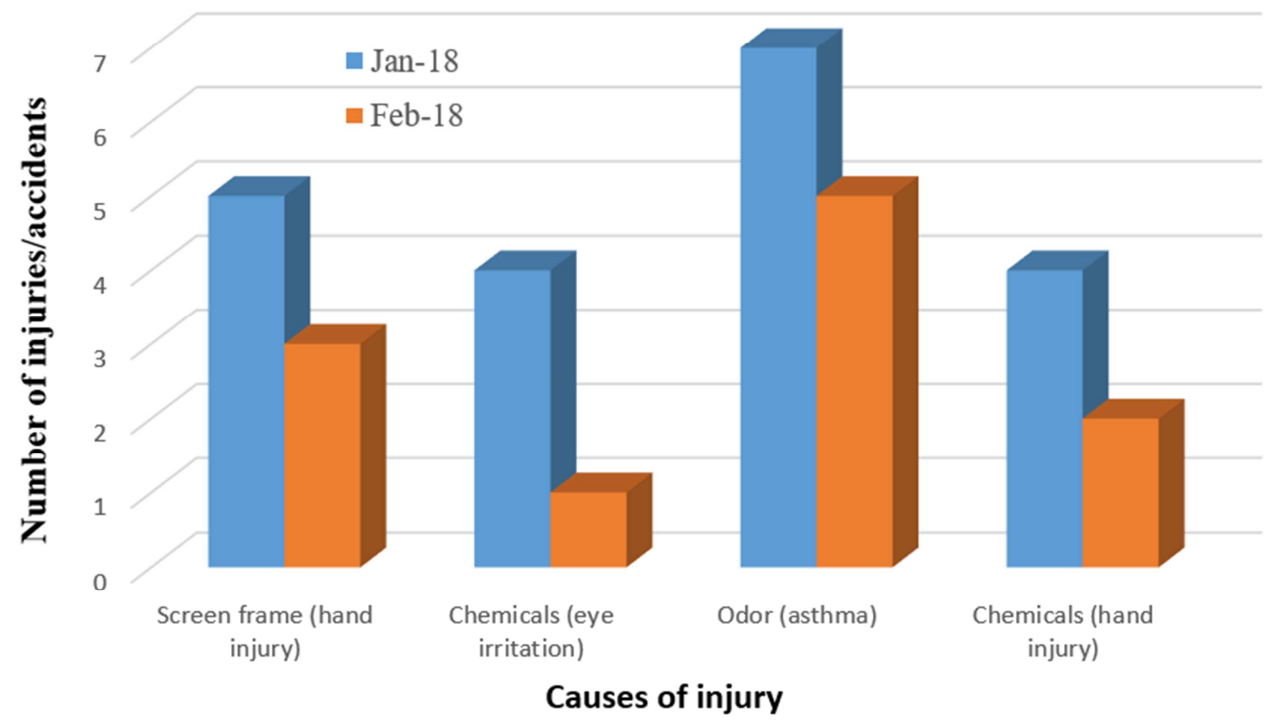

Figure 8. Comparison of injury/accident reduction in printing section between the months.

\subsection{Rate of Minimization of Injury and Accidents}

It is very important to find the number of injuries or accidents of both the months that would be required to calculate the minimization rate of injury and accidents.
Figure 9 shows the number of injury/accident in different sections in January 2018 is 178 and in February 2018 are 112. Therefore, rate of minimization of injury/accidents can be calculated as follows:

(1) Rate of minimization of injury/accidents $=\frac{\text { Total injury in January } 2018-\text { Total injury in February } 2018}{\text { Total injury in January } 2018} \times 100$

$$
\begin{gathered}
=\frac{178-112}{178} \times 100 \\
=37.07 \%
\end{gathered}
$$

Total number of injuries/accidents found in different sections in Jan-18 and Feb-18

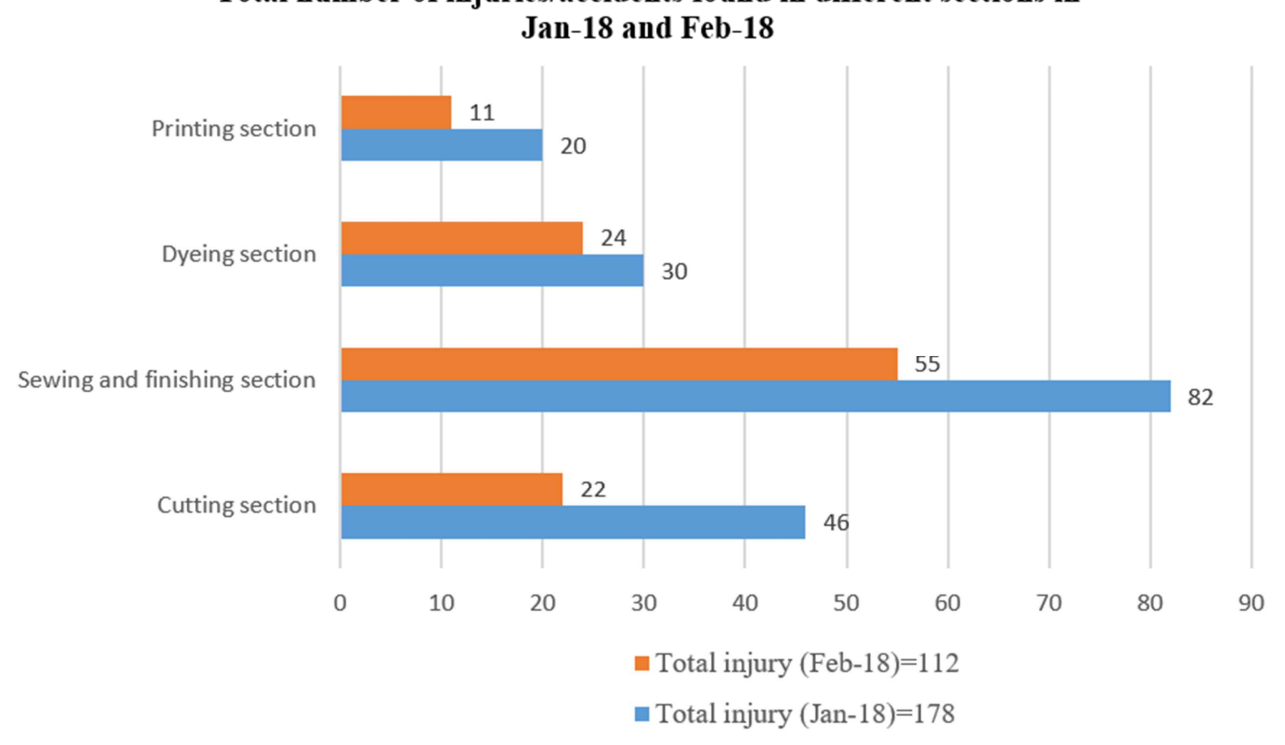

Figure 9. Total number of injury/accident in different sections between the months. 


\section{Conclusion}

Risk of accidental causes and injury in readymade garment sectors are burning topic in the economy of Bangladesh from the last two decades. Being strength of national economy, still risk and accidental injuries are the main responsible hindrance for the development of fast growing RMG sectors in Bangladesh [19]. The study of occupational health and safety in textile industry examines to promote health and safety to the workers in the industry by minimizing the causes of risk. The hazards and risk involved in the textile industry is high compared with other industries and least importance is given to textile industries [20]. Most of accident does not come to the legal formalities. Still much more research is to be done for improving the occupational health research. The measures such as creation of advanced research facilities, human resources development, creation of environmental and occupational health cells and development of database and information system should be taken. If we want to make a positive view of RMG industry to the buyer of foreign countries, risk factors found should be controlled strictly and risk management technique and regulation should be followed by the respective authority.

\section{References}

[1] Beriha, Shankar, Gouri, "Occupational Health and Safety (OHS) Issues in Social Marketing" National Institute of Technology Rourekia - 769008, INDIA; March 2012.

[2] Mehedi Ahmed Ansary, Uttama Barua, Workplace Safety Compliance of RMG Industry in Bangladesh: Structural Assessment of RMG Factory Buildings, International Journal of Disaster Risk Reduction, 14, 424-437, 2015.

[3] Md. Morshedul Hasan, Appel Mahmud, Md. Samiul Islam, Deadly Accidents in Bangladeshi Apparel Industry and Illustrating the Causes and Effects of These Incidents, Journal of Finance and Accounting, 5 (5): 193-199, 2017.

[4] Uddin, M., Adnan, A., Sultana, N., Muktadir, M., Fire Safety and Security System in High-rise Buildings in Tangail Pourashava, Journal of Environmental Science and Natural Resources, 10 (1), 33-40, 2017.

[5] Kallol Kumar Samaddar, Occupational Health and Safety Management In RMG Sector of Bangladesh, International Journal of Scientific \& Technology Research, Volume 5, Issue 12, December 2016.

[6] Claude J. Romer, The Importance of Accident and Injury Prevention, ERGONOMICS, Vol. 30, p. 173-179, 1987.

[7] C. D. Kane, "Environmental and Health Hazard in Spinning Industries and their Control", Indian Journal of Fiber and Textile Research, Vol. 26, p. 39-43, 2001.
[8] Z. Amin, R. Mohammad, S. Abdul Aziz and N. Othman, "Workers' Safety Awareness Level on Hand Related Injury and Accident in Metal Fabrication Industry", Journal of Advanced Research in Applied Sciences and Engineering Technology, Vol. 1, No. 1, 2015, p. 1-12, 2015.

[9] Afamdi O. Ezenwa, "A study of fatal injuries in Nigerian factories”, Occupational Medicine, Vol. 51, Issue 8, p. 485489, 2001.

[10] S. Calvin and Bobby Joseph, "Occupation Related Accidents in Selected Garment Industries in Bangalore City", Indian Journal of Community Medicine, Vol. 31, No. 3, JulySeptember, 2006

[11] Waqas Ahmed Khan, Talha Mustaq and Anmol Tabassum, "Occupational Health and Safety and Risk Analysis", International Journal of Science, Environment and Technology, Vol. 3, No. 4, p. 1336-1346, 2014.

[12] Kirsten Jorgensen, "Concepts of Accident Analysis", Encyclopedia of Occupational Health and Safety (Part VIII: Accident and Safety Management), March 30, 2011.

[13] K. Raman, "Industrial eye accident prevention in textile mills", Indian Journal of Ophthalmology, Vol. 16, Issue 4, p. 196-197, 1968.

[14] Praveen Kumar M, Mugundhan K and Visagavel K "Occupational Health and Safety in Textile Industry" International Journal of Research in Engineering and Technology, Vol. 3, Issue 11, p. 168-172, 2014.

[15] Mustafa SERINNKEN, Ibrahim TÜRKÇÜER, Bekir DAĞLI, Özgür KARCIOĞLU, Mehmet ZENCIR and Emrah UYANIK, "Work-related injuries in textile industry workers in Turkey", Turkish Journal of Trauma \& Emergency Surgery, Vol. 18 (1), p. 31-36, 2012.

[16] Muhammad Faisol Chowdhury and Tasnim Rezoana Tanim, "Industrial Accidents in Bangladesh Apparel Manufacturing Sector: An Analysis of the Two Deadliest Accidents in History", Asian Journal of Social Sciences and Management Studies, Vol. 3 (2), p. 115-126, 2016.

[17] Ma, yun, Jian, "Analysis on the Fire Risk Existing in the Storage of Textile Materials and Textile Goods" Procedia Engineering, p. 271-275, 2014.

[18] Safety Data Sheets for Hazardous Chemicals Information Sheet, HEALTH AND SAFETY AUTHORITY, Updated Sept 2018.

[19] Abir, Mahmud, Tareq, "Haphazard Industrialization and The Risk of Fire In Dhaka" International J0urnal of Research in Applied Science; ISSN (E): 2321-8851; ISSN (P): 2347-4580; Volume-2, November 2014.

[20] Tareq Mahmud Abir, "Applied Haphazard Industrialization And The Risk Of Fire A Study On Garments Industries In Dhaka" International Journal of Research in Applied, Natural and Social Sciences, Vol. 2, Issue 11, p. 25-34, 2014. 